\title{
Human bone marrow-derived mesenchymal stem cell gene expression patterns vary with culture conditions
}

\author{
Myoung Woo Lee", Dae Seong Kim”, Keon Hee Yoo, Hye Ryung Kim, In Keun Jang, Ji Hyang Lee, So Yeon \\ Kim, Meong Hi Son, Soo Hyun Lee, Hye Lim Jung, Ki Woong Sung, Hong Hoe Koo \\ Department of Pediatrics, Samsung Medical Center, Sungkyunkwan University School of Medicine, Seoul, Korea
}

p-ISSN 2287-979X / e-ISSN 2288-0011 http://dx.doi.org/10.5045/br.2013.48.2.107 Blood Res 2013;48:107-14

Received on November 21, 2012 Revised on January 30, 2013 Accepted on May 17, 2013

\#Myoung Woo Lee and Dae Seong Kim contributed equally to this work.

*This research was supported by Basic Science Research Program through the National Research Foundation of Korea funded by the Ministry of Education, Science and Technology (2009-0089787), by IN-SUNG Foundation for Medical Research, and by Samsung Biomedical Research Institute (Grant \#SBRI C-B0-204).

\section{Correspondence to}

Hong Hoe Koo, M.D., Ph.D.

Keon Hee Yoo, M.D, Ph.D.

Department of Pediatrics, Samsung

Medical Center, 81, Irwon-ro, Gangnam-gu, Seoul 135-710, Korea

Tel: H.H.K., +82-2-3410-3524

K.H.Y., + 82-2-3410-3532

Fax: H.H.K., +82-2-3410-0043

K.H.Y., +82-2-3410-0043

E-mail: H.H.K., hhkoo@skku.edu K.H.Y., hema2170@skku.edu

C) 2013 Korean Society of Hematology

\section{Background}

Because of the heterogeneity of human mesenchymal stem cells (MSCs), methods for cell expansion in culture and the effects on gene expression are critical factors that need to be standardized for preparing MSCs. We investigated gene expression patterns of MSCs with different seeding densities and culture times.

Methods

Bone marrow-derived MSCs were plated at densities from 200 cells $/ \mathrm{cm}^{2}$ to 5,000 cells $/ \mathrm{cm}^{2}$, and the gene expression patterns were evaluated over time using a reverse-transcription polymerase chain reaction assay.

Results

The mRNA levels of factors that play a critical role in cell migration and tissue regeneration, such as podocalyxin-like protein (PODXL), $\alpha 4$-integrin, $\alpha 6$-integrin, and leukemia inhibitory factor (LIF), were higher in MSCs plated at 200 cells $/ \mathrm{cm}^{2}$ than in MSCs plated at 5,000 cells $/ \mathrm{cm}^{2}$. The mRNA levels of these factors gradually increased for 10 days and then decreased by day 15 in culture. MSCs seeded at 200 cells $/ \mathrm{cm}^{2}$ that were cultured for 10 days expressed high levels of Oct-4 and Nanog. Indoleamine 2,3-dioxygenase, cyclooxygenase-1, and hepatocyte growth factor expression were upregulated in the presence of the proinflammatory cytokine interferon- $\gamma$ in these cells.

\section{Conclusion}

We found differences in the gene expression patterns of MSCs under different culture conditions. MSCs from 10-day cultures seeded at a low density were efficiently expanded, expressed PODXL, $\alpha 6$-integrin, $\alpha 4$-integrin, and LIF, and maintained properties like stemness and immunomodulation. Therefore, ex vivo expansion of MSCs maintained for an adequate culture time after plating at low cell density can provide an effective regenerative medicinal strategy for cell therapies using MSCs.

Key Words Mesenchymal stem cell, Gene expression pattern, Seeding density, Culture time, Cell therapy

\section{INTRODUCTION}

Mesenchymal stem cells (MSCs) are known to have significant potential for cell therapies, including cell-based transplantations and regenerative medicine, owing to their homing ability, engraftment efficiency, and therapeutic value following a homing event, as evidenced by differentiation into tissue-specific cell types $[1,2]$ and potent immuno- suppressive effects $[3,4]$. However, the results have been variable in part, which may reflect the intrinsic heterogeneity of MSCs, as well as differences in culture conditions for isolated MSCs.

MSCs exhibit heterogeneous characteristics with regard to morphology, proliferation rate, and secreted factors. Previous studies have attempted to characterize the heterogeneity of these cells, and preclinical trials using cells based on the intrinsic heterogeneity have been conducted [5-9]. 
Numerous attempts have been made to develop more specific procedures for the isolation and preparation of appropriate cells from this heterogeneous cell population. In particular, ex vivo expansion of MSCs is used for developing and maintaining the cells used for cell therapy. The methods used to expand and characterize the cells are critical factors in preparing MSCs. However, adequate protocols for preparing and characterizing MSCs have not yet been standardized. Although ex vivo expansion of MSCs is one of the alternative strategies for overcoming intrinsic heterogeneity, several recently studies have shown that low initial plating densities could be beneficial for the optimal ex vivo expansion of MSCs and their subsequent differentiation [10-12].

Podocalyxin-like protein (PODXL), $\alpha 6$-integrin, and $\alpha 4$-integrin are known to contribute to hematopoietic stem cell homing to the bone marrow (BM) [13], as well as the clonogenicity of MSCs and their migration to damaged tissues [5]. Leukemia inhibitory factor (LIF) also regulates humoral and cellular immune responses in damaged tissues [14] and induces the in vivo expansion of BM progenitor cells that accelerates hematopoietic reconstitution [15]; thus, it supports hematopoiesis and enables the maintenance of a highly enriched, competitive, and repopulation of stem cells [16].

In this study, we explored differences in the expression of PODXL, $\alpha 4$-integrin, $\alpha 6$-integrin, and LIF genes that play a crucial role in cell migration and tissue regeneration in BM-MSCs expanded under various seeding densities and cultivation times. In addition, we confirmed the expression of stemness and immunomodulatory genes in BM-MSCs under appropriate culture conditions under which those genes were highly expressed. Ex vivo expansion of MSCs maintained for an adequate seeding density and culture time after plating at low cell density could provide a promising strategy for enhancing regenerative properties of MSCs.

\section{MATERIALS AND METHODS}

\section{Isolation and culture of human BM-MSCs}

The Institutional Review Board of Samsung Medical Center approved this study. After obtaining written informed consent from the patients, we obtained iliac crest BM aspirates from normal adult volunteers. Mononuclear cells were isolated from normal BM aspirates by using Ficoll-Hypaque (Histopaque-1077; Sigma-Aldrich, St. Louis, MO) density gradient centrifugation. Cells were plated at $3 \times 10^{5}$ cells $/ \mathrm{cm}^{2}$ in low glucose Dulbecco's Modified Eagle's Medium (LGDMEM; Invitrogen-Gibco, Rockville, MD) containing 10\% fetal bovine serum (FBS; Invitrogen-Gibco) and $100 \mathrm{U} / \mathrm{mL}$ penicillin/streptomycin (Invitrogen-Gibco). After $24 \mathrm{~h}$, nonadherent cells were removed. Adherent cells were cultured for an additional 5-10 days, until they were $\sim 70 \%$ confluent.

\section{Flow cytometry}

Antibodies against the human antigens CD14, CD34, CD45, CD73, and CD90 were purchased from Becton Dickinson (Franklin Lakes, NJ). Antibodies against CD105 were purchased from Ancell (Bayport, MN). A total of $5 \times 10^{5}$ cells were resuspended in $0.2 \mathrm{~mL}$ PBS and incubated with fluorescein isothiocyanate- or phycoerythrin-conjugated antibodies for $20 \mathrm{~min}$ at room temperature. The fluorescence intensity of the cells was evaluated by flow cytometry (FACScan; Becton Dickinson), and data were analyzed with CELLQUEST software (Becton Dickinson).

\section{Differentiation of MSCs}

\section{Osteogenic differentiation}

First passage MSCs were plated at $5 \times 10^{5}$ cells/well in 6-well plates in LG-DMEM containing 10\% FBS, allowed to adhere overnight, and replaced with LG-DMEM containing 10\% FBS supplemented with $0.1 \mu \mathrm{M}$ dexamethasone (SigmaAldrich), $10 \mathrm{mM} \beta$-glycerolphosphate (Sigma-Aldrich), and $100 \mu \mathrm{M}$ ascorbate-2-phosphate (Sigma-Aldrich). The medium was changed every 3 days. After 14-21 days, osteoblast differentiation was determined by alkaline phosphatase expression.

\section{Adipogenic differentiation}

As described above, cells were cultured for 14-21 days after reaching confluence in LG-DMEM containing 10\% FBS, $1 \mu \mathrm{M}$ dexamethasone, $500 \mu \mathrm{M}$ isobutyl methylxanthine (Sigma-Aldrich), $100 \mu \mathrm{M}$ indomethacin (Sigma-Aldrich), and $10 \mu \mathrm{g} / \mathrm{mL}$ insulin (Sigma-Aldrich). Adipogenic differentiation was evaluated by detecting cellular accumulation of neutral lipid vacuoles via staining with Oil-red O (SigmaAldrich) solution.

\section{Chondrogenic differentiation}

A total of $1 \times 10^{6}$ cells were pelleted in a $15-\mathrm{mL}$ tube by centrifugation at $300 \times g$ for $5 \mathrm{~min}$. Pelleted cells were cultured for 14-21 days after reaching confluence in LG-DMEM containing 1× insulin-transferrin-selenium (ITS; Invitrogen-Gibco), $1 \mathrm{mM}$ sodium pyruvate (InvitrogenGibco), $0.1 \mu \mathrm{M}$ dexamethasone, $397 \mu \mathrm{g} / \mathrm{mL}$ ascorbate-2-phosphate, and $10 \mathrm{ng} / \mathrm{mL}$ transforming growth factor- $\beta_{1}$ (R\&D Systems, Minneapolis, MN). Chondrogenic induction was evaluated at $80 \%$ confluence by detecting extracellular accumulation of chondrocyte matrix by toluidine blue (SigmaAldrich) staining.

\section{Cell counting}

Second-passage MSCs were used throughout these studies. MSCs seeded at a density of 200, 1,000, and 5,000 cells/ $\mathrm{cm}^{2}$ were observed on day 5,10 , and 15 of culture with an inverted microscope (Olympus CK40; Olympus, Melville, NY). The total cell number of MSCs was determined using a hematocytometer (Marienfeld, Germany).

\section{RNA extraction and RT-PCR analysis}

Viable first-passage MSCs were plated at 200, 1,000, and 5,000 cells $/ \mathrm{cm}^{2}$ and incubated for 5, 10, and 15 days each. To obtain interferon (IFN)- $\gamma$-treated MSCs, MSCs plated at 200 cells $/ \mathrm{cm}^{2}$ that were cultured for 10 days were incubated 
Table 1. Primer sequences for RT-PCR analysis.

\begin{tabular}{|c|c|c|c|c|}
\hline Target & Primer sequence $^{\text {a) }}$ & Annealing time and temperature & Cycle number & Product size (bp) \\
\hline \multirow[t]{2}{*}{ PODXL } & F 5'-TTTTAСТСТTGСССТСТC-3' & $30 \mathrm{sec}, 50^{\circ} \mathrm{C}$ & 37 & 116 \\
\hline & R 5'-CTTTCTTTCTGCCAAGAAAC-3' & & & \\
\hline \multirow[t]{2}{*}{$\alpha 6$-integrin } & F 5'-AAGGCTCCTGTTTTGCACAG-3' & $30 \mathrm{sec}, 60^{\circ} \mathrm{C}$ & 35 & 111 \\
\hline & R 5'-ATGTAAGTCAGCCA-CGCCA-3' & & & \\
\hline \multirow[t]{2}{*}{$\alpha 4$-integrin } & F 5'-GGGTAGTGGCCGTTTAGTGTTGAA-3' & $30 \mathrm{sec}, 62^{\circ} \mathrm{C}$ & 31 & 310 \\
\hline & R 5'-ATTGATCACTGAAGCGTTGGCGAG-3' & & & \\
\hline \multirow[t]{2}{*}{ LIF } & F 5'-AGGATGGGCTTCGAGAAAGA-3' & $30 \mathrm{sec}, 60^{\circ} \mathrm{C}$ & 30 & 100 \\
\hline & R 5'-CACGCAAAGGCTCTGTGATT-3' & & & \\
\hline \multirow{2}{*}{ CXCR4 } & F 5'-GGTGGTCTATGTTGGCGTCT-3' & $30 \mathrm{sec}, 66^{\circ} \mathrm{C}$ & 33 & 227 \\
\hline & R 5'-TGGAGTGTGACAGCTTGGAG-3' & & & \\
\hline \multirow{2}{*}{ OCT4 } & F 5'-AAG-CGATCAAGCAGCGACTA-3' & $30 \mathrm{sec}, 58^{\circ} \mathrm{C}$ & 32 & 230 \\
\hline & R 5'-CCTCAGTTTGAATGCATGGG-3 & & & \\
\hline \multirow{2}{*}{ Nanog } & F 5'-CAGAAAAACAACTGGCCGAA-3' & $30 \mathrm{sec}, 65^{\circ} \mathrm{C}$ & 33 & 246 \\
\hline & R 5'-GGCCTGATTGTTCCAGGATT-3' & & & \\
\hline \multirow[t]{2}{*}{$I D O$} & F 5'-CGCTGTTGGAAATAGCTTC-3' & $30 \mathrm{sec}, 60^{\circ} \mathrm{C}$ & 30 & 234 \\
\hline & R 5'-CAGGACGTCAAAGCACTGAA-3' & & & \\
\hline \multirow[t]{2}{*}{ IL-10 } & F 5'-ATCCAAGACAACACTACTAA-3' & $40 \mathrm{sec}, 55^{\circ} \mathrm{C}$ & 30 & 588 \\
\hline & R 5'-TAAATATCСТCAАAGTTCC-3' & & & \\
\hline \multirow[t]{2}{*}{ COX-1 } & F 5'-GAGTTTGTCAATGCCACCT-3' & $30 \mathrm{sec}, 58^{\circ} \mathrm{C}$ & 30 & 215 \\
\hline & R 5'-CAACTGCTTCTTCCСТTTG-3' & & & \\
\hline \multirow[t]{2}{*}{$\mathrm{COX}-2$} & F 5'-TCCTTGCTGTTCCСАСССАTG-3' & $30 \mathrm{sec}, 60^{\circ} \mathrm{C}$ & 30 & 847 \\
\hline & R 5'-CATCATCAGACCAGGCACCAG-3' & & & \\
\hline \multirow[t]{2}{*}{ HGF } & F 5'-ATGCATCCAAGGTCAAGGAG-3' & $30 \mathrm{sec}, 65^{\circ} \mathrm{C}$ & 32 & 349 \\
\hline & R 5'-TTCCATGTTCTTTTGTCCCACA-3' & & & \\
\hline \multirow[t]{2}{*}{ GAPDH } & F 5'-ATCACCATCTTCCA-GGAGCG-3' & $30 \mathrm{sec}, 62^{\circ} \mathrm{C}$ & 24 & 573 \\
\hline & R 5'-GTTCTTCCACCACTTCGTCC-3' & & & \\
\hline
\end{tabular}

${ }^{a)}$ Forward $(\mathrm{F})$ and reverse $(\mathrm{R})$ primers used to detect mRNA expression of the indicated targets.

Abbreviations: PODXL, Podocalyxin-like protein; LIF, leukemia inhibitory factor; CXCR4, C-X-C chemokine receptor type 4; IDO, indoleamine 2,3-dioxygenase; IL-10, interleukin-10; COX-1, cyclooxygenase-1; COX-2, cyclooxygenase-2; HGF, hepatocyte growth factor; GAPDH, glyceraldehyde-3-phosphate dehydrogenase.

in the presence of $200 \mathrm{IU} / \mathrm{mL} \mathrm{IFN}-\gamma$ (R\&D Systems) for $48 \mathrm{~h}$. Total RNA was isolated from $10^{6}$ cells by using the QIAGEN RNeasy Mini Kit (Qiagen, Valencia, CA), which was used to perform semi-quantitative reverse-transcription PCR assays with a commercial kit (PrimeScript $1^{\text {st }}$ strand cDNA synthesis kit; TaKaRa Shuzo, Shiga, Japan). Band intensity was measured using NIH image/ImageJ and normalized against that of GAPDH mRNA. cDNAs were amplified using the primers shown in Table 1.

\section{Statistical analysis}

Data are expressed as the mean \pm standard deviation.

\section{RESULTS}

Characteristics of BM-derived MSCs cultured at various seeding densities for different times

Human BM-derived MSCs were fibroblastic in shape. The cell surface antigen profiles of these cells after 2 passages in culture were analyzed by flow cytometry. The cells were positive for MSC-specific surface markers such as CD73, CD90, and CD105, but negative for CD14 and CD45 (Fig. 1A). The cells also exhibited mesenchymal differentiation potential, as assessed by culturing cells in osteogenic, chondrogenic, or adipogenic medium (Fig. 1B). Viable first-pas- sage MSCs were plated at 200, 1,000, and 5,000 cells $/ \mathrm{cm}^{2}$ and incubated for 5, 10, and 15 days (Fig. 2), and their yields were determined (Fig. 3). Cultures plated at a density of 200 cells $/ \mathrm{cm}^{2}$ were $\sim 50 \%$ confluent $(7,800 \pm 1,200$ cells/ $\mathrm{cm}^{2}$ ) after 10 days, and most cells were thin and spindle-shaped. Cultures plated at 1,000 cells $/ \mathrm{cm}^{2}$ were $\sim 100 \%$ confluent (approximately $9,500 \pm 1,400$ to $42,000 \pm 3,100$ cells/ $\mathrm{cm}^{2}$ ) after 5-15 days of culture. Cultures plated at 5,000 cells $/ \mathrm{cm}^{2}$ were over-confluent, such that the cell yields were approximately $24,300 \pm 4,700$ to $48,400 \pm 4,900$ cells $/ \mathrm{cm}^{2}$ after 515 days, and most cells showed extensive cell-to-cell contacts.

Comparison of gene expression in BM-MSC cultures relative to seeding density and culture time

PODXL, $\alpha 4$-integrin, $\alpha 6$-integrin, and LIF are all linked to cell motility and migration $[13,17,18]$. After verifying the mRNA expression of PODXL, $\alpha 4$-integrin, $\alpha 6$-integrin, and $\mathrm{C}-\mathrm{X}-\mathrm{C}$ chemokine receptor type 4 (CXCR4) in MSCs plated at 500 cells $/ \mathrm{cm}^{2}$, which is equivalent to a $50 \%$ confluent seeding density, the gene expression levels of MSCs plated at low or high densities were examined. RT-PCR revealed that PODXL, $\alpha 4$-integrin, $\alpha 6$-integrin, and LIF transcripts were present at the highest levels in 10-day MSC cultures seeded at a density of 200 cells $/ \mathrm{cm}^{2}$ (Fig. 4). The PODXL mRNA levels were the highest in 10-day MSC cul- 

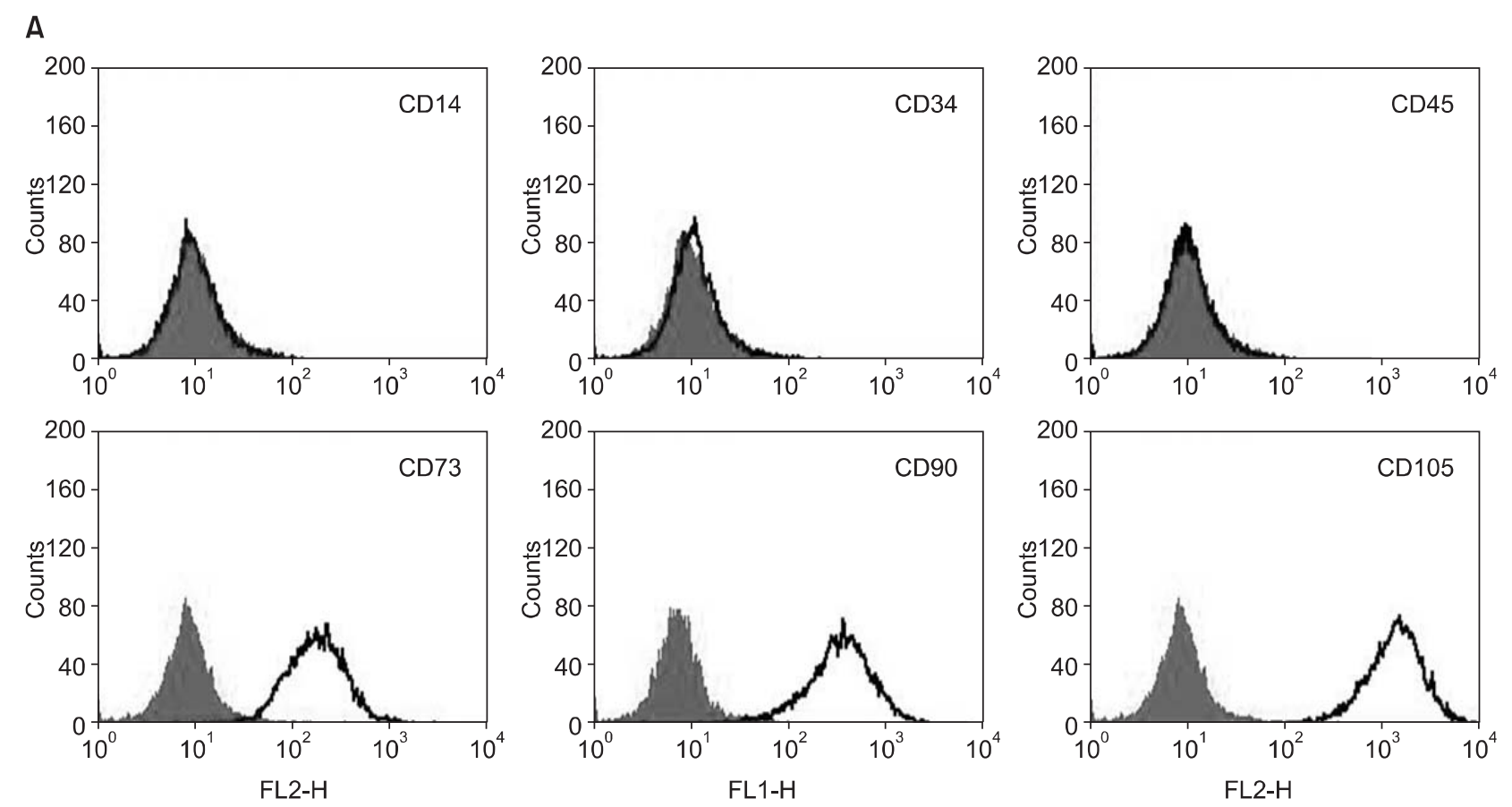

B

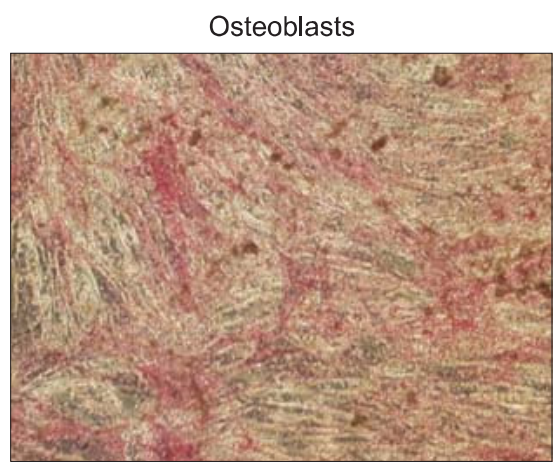

Alkaline phosphatase

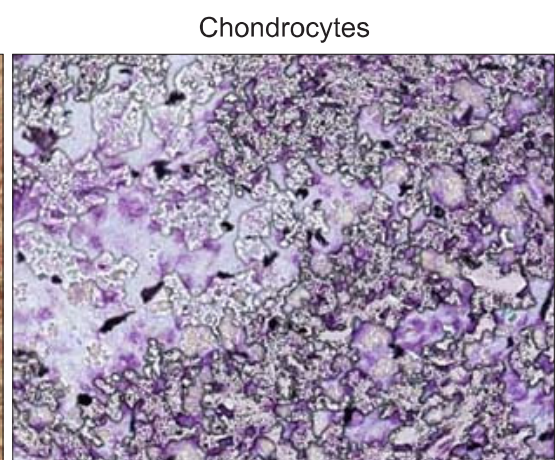

Toluidine blue

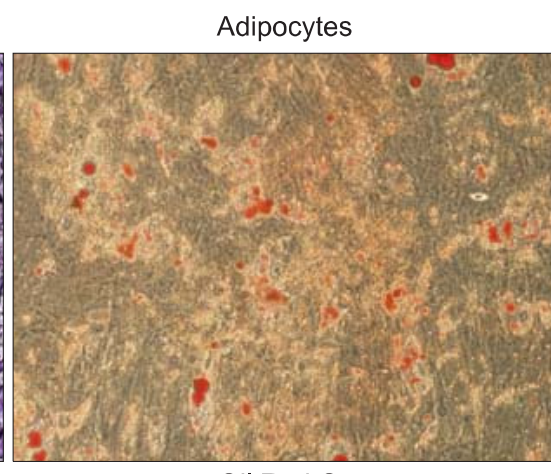

Oil Red O

Fig. 1. Characteristics of MSCs isolated from human bone marrow. (A) Flow cytometric analysis of MSC cell surface markers. The isolated cells were positive for CD73, CD90, and CD105 but negative for CD14, CD34, and CD45. (B) Differentiation of BM-MSCs. First passage BM-MSCs were incubated for 14-21 days in the presence of specific differentiation agents for osteoblasts, chondrocytes, and adipocytes. Alkaline phosphatase staining shows mineralization of the extracellular matrix. Toluidine blue staining shows the deposition of proteoglycans and lacunae. Differentiation into the adipocyte lineage was demonstrated by staining with Oil Red $O(\times 200)$.

tures seeded at densities of 200 or 1,000 cells $/ \mathrm{cm}^{2}$. The mRNA levels of $\alpha 4$-integrin, $\alpha 6$-integrin, and LIF were highest in cultures seeded at $200 \mathrm{cells} / \mathrm{cm}^{2}$, which were reduced when the cells were seeded at 1,000 or 5,000 cells $/ \mathrm{cm}^{2}$. The mRNA levels of CXCR4 and hepatocyte growth factor (HGF) were not significantly different under any culture conditions.

Stemness and immunomodulatory properties of MSCs plated at 200 cells $/ \mathrm{cm}^{2}$

RT-PCR assays showed that Oct-4 and Nanog were expressed in MSCs seeded at a density of 200 cells $/ \mathrm{cm}^{2}$ and cultured for 10 days (Fig. 5). To assess the immunomodulatory properties of these MSCs after 10 days in culture, the expression levels of immunomodulatory genes were analyzed.
The mRNA expression levels of indoleamine 2,3-dioxygenase (IDO), cyclooxygenase (COX)-1, COX-2, and HGF was low in MSCs from all culture conditions, but that of interleukin (IL)-10 was high (Fig. 6). MSCs have been shown to retain their immunomodulatory properties in the presence of proinflammatory cytokines, for example, at inflammation sites in vivo that are rich in proinflammatory cytokines, especially IFN- $\gamma[19,20]$. MSCs cultured for 10 days after plating at 200 cells $/ \mathrm{cm}^{2}$ were incubated in the presence of $200 \mathrm{IU} / \mathrm{mL}$ IFN- $\gamma$ for $48 \mathrm{~h}$. IFN- $\gamma$ treatment significantly upregulated IDO, COX-2, and HGF expression in MSCs seeded at 200 cells $/ \mathrm{cm}^{2}$ and cultured for 10 days (Fig. 6). These data support the retention of an immunomodulatory role for MSCs. 


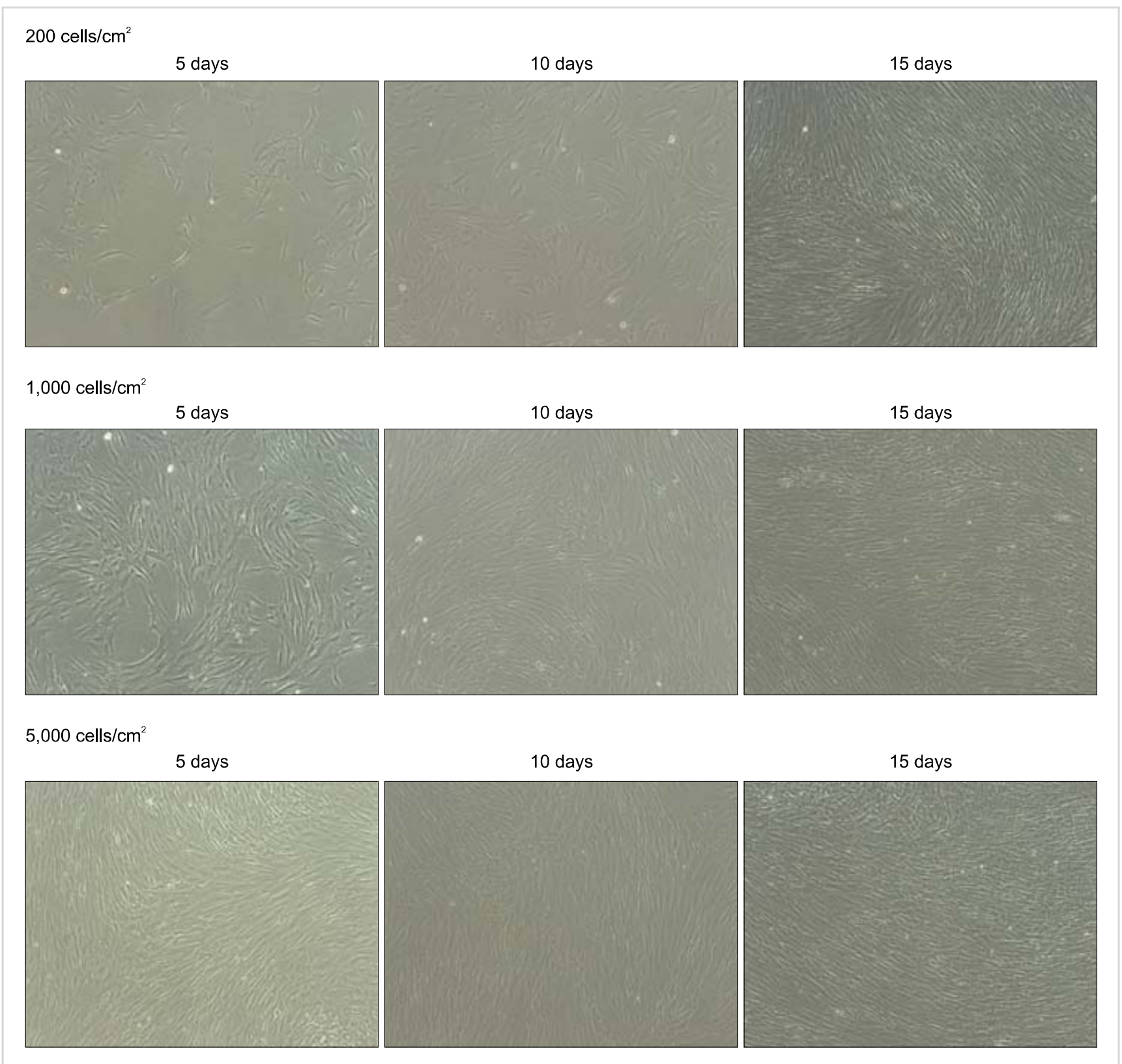

Fig. 2. Phase-contrast micrograph of BM-MSCs obtained from 5-, 10-, and 15-day cultures after seeding at a density of 200, 1,000, and 5,000 cells $/ \mathrm{cm}^{2}(\times 40)$. BM-MSCs seeded at a density of $200,1,000$, and $5,000 \mathrm{cells} / \mathrm{cm}^{2}$ were observed after 5,10 , and 15 days in culture with an inverted microscope.

\section{DISCUSSION}

The heterogeneity of MSCs and differences in conditions used to culture MSCs may be the main causes of the contradictory results from numerous studies and clinical trials. As a result, the methods by which the cells are expanded in culture and characterized are critical factors in terms of preparing MSCs with the desired features. By expanding MSCs ex vivo for 10 days after seeding at 200 cells $/ \mathrm{cm}^{2}$, we obtained cells expressing PODXL, $\alpha 6$-integrin, $\alpha 4$-integrin, and LIF. Several studies have demonstrated that the "stemness" of MSCs, as characterized by their high pro- liferative potential and self-renewal capacity, is important for biomedical applications [7, 9, 21]. MSCs in low-density cultures contain a subpopulation of rapidly self-replicating cells [6-9] that could have a greater capacity to generate single-cell-derived clones through rapid proliferation compared to MSCs in high-density cultures. The surface protein characteristics of MSCs, including PODXL and $\alpha 6$-integrin, are known to reappear when subconfluent cultures are replated at low densities [5]; this finding indicates that surface proteins could be used to identify primitive cells in cultures. The genes for PODXL, $\alpha 6$-integrin, $\alpha 4$-integrin, and LIF were expressed at high levels in MSCs cultured at low density, but this does not imply that all MSCs plated at a low density 
A

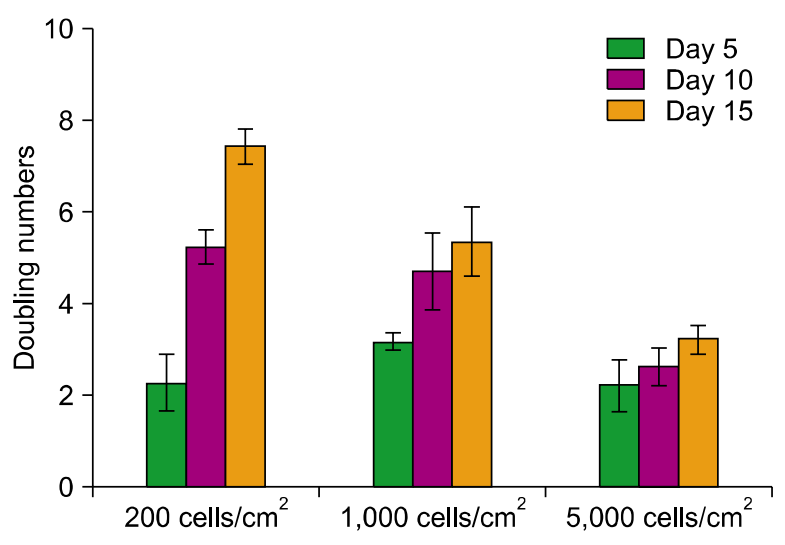

B

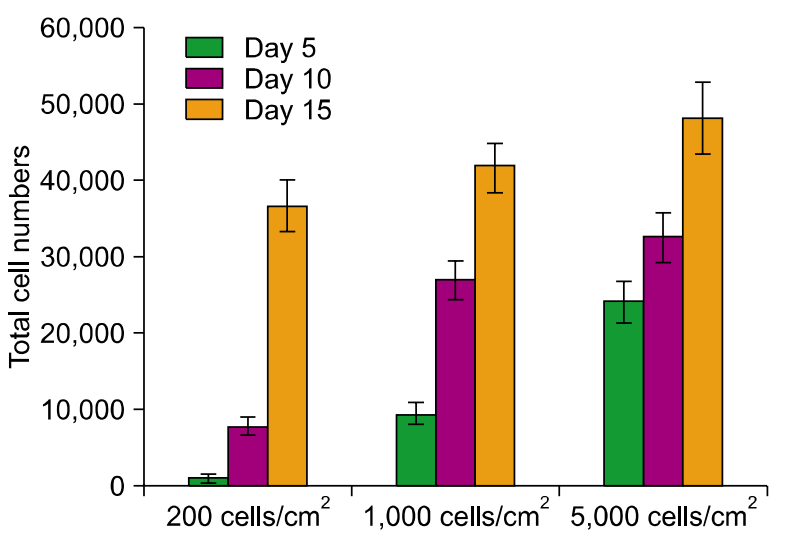

Fig. 3. Cell density of MSCs obtained from 5-, 10-, and 15-day cultures after seeding at a density of 200, 1,000, and 5,000 cells/ $/ \mathrm{cm}^{2}$. Doubling numbers (A) and total cell numbers (B) of MSCs obtained from 5-, 10-, and 15-day cultures after seeding at a density of 200, 1,000, and 1,000 cells $/ \mathrm{cm}^{2}$. Approximately $10^{5} \mathrm{MSCs}$ were thawed, plated in 174- $\mathrm{cm}^{2}$ dishes, incubated for 4 days, and then replated at 200, 1,000, and 5,000 cells $/ \mathrm{cm}^{2}$ on the following day and cultured for 5,10 , and 15 days. The number of MSCs were counted using a hematocytometer.

\begin{tabular}{|c|c|c|c|c|c|c|c|c|c|}
\hline \multicolumn{3}{|c|}{200 cells $/ \mathrm{cm}^{2}$} & \multicolumn{3}{|c|}{1,000 cells $/ \mathrm{cm}^{2}$} & \multicolumn{3}{|c|}{5,000 cells $/ \mathrm{cm}^{2}$} & \multirow[b]{2}{*}{ days } \\
\hline 5 & 10 & 15 & 5 & 10 & 15 & 5 & 10 & $15 \mathrm{~d}$ & \\
\hline 0.60 & 1.01 & 0.67 & 0.32 & 0.93 & 0.50 & 0.59 & 0.59 & 0.40 & \\
\hline$=i$ & 0 & 98 & $e_{-6}$ & $\mathrm{C}$ & es & $\mathrm{Cn}$ & e.9.8 & e. & $P O D X L$ \\
\hline 0.81 & 1.10 & 0.89 & 0.54 & 0.73 & 0.67 & 0.61 & 0.54 & 0.50 & \\
\hline 0 & & $\infty$ & 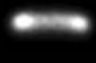 & & & $=$ & $\Leftrightarrow$ & $=$ & 6-integrin \\
\hline 0.36 & 1.10 & 0.99 & 0.09 & 0.89 & 0.71 & 0.32 & 0.64 & 0.28 & \\
\hline$=$ & 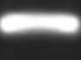 & $\infty$ & a & $\infty$ & $=$ & $=$ & $=$ & $=$ & a4-integrin \\
\hline 0.76 & 1.23 & 0.40 & 0.12 & 0.57 & 0.47 & 0.25 & 0.08 & 0.58 & \\
\hline 0 & & $=$ & 2 & $=$ & $=0$ & 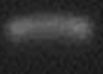 & & 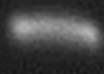 & LIF \\
\hline 0.77 & 1.07 & 0.76 & 0.87 & 0.76 & 0.98 & 0.89 & 0.74 & 0.63 & \\
\hline 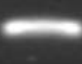 & & 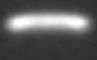 & & & & & 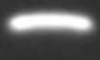 & - & CXCR4 \\
\hline 0.77 & 0.95 & 0.82 & 0.41 & 0.78 & 0.71 & 0.70 & 0.64 & 0.74 & \\
\hline- & - & $=$ & $=$ & - & - & - & - & - & $H G F$ \\
\hline 1.00 & 1.00 & 1.00 & 1.00 & 1.00 & 1.00 & 1.00 & 1.00 & 1.00 & \\
\hline
\end{tabular}

Fig. 4. RT-PCR analysis of MSCs after seeding at different densities and culturing for varying times. Total RNA of MSCs, obtained at 5, 10 , and 15 days after plating at 200, 1,000, and 5,000 cells $/ \mathrm{cm}^{2}$, was analyzed by RT-PCR with primers specific for PODXL, $\alpha 6$ integrin, $\alpha 4$-integrin, LIF, CXCR4, and HGF. Quantitative gene expression data of each candidate gene indicates mRNA expression relative to GAPDH mRNA. will express these factors regardless of the culture time. Interestingly, the mRNA levels of these factors gradually increased over 10 days and then decreased by 15 days in culture. The expression level gradually changed with increasing seeding cell density. Therefore, the ex vivo expansion of MSCs plated at low densities must be maintained for an adequate culture time (e.g., 10 days).
MSCs expanded ex vivo for 10 days after seeding at 200 cells $/ \mathrm{cm}^{2}$ showed higher gene expression of PODXL, $\alpha 6$-integrin, $\alpha 4$-integrin, and LIF. The expression of these genes could contribute to enhancing migration and intercellular communication, as well as homing of hematopoietic stem and progenitor cells to the BM and MSCs to damaged tissues $[5,13]$. Confluent cultures of MSCs are useful for therapeutic 


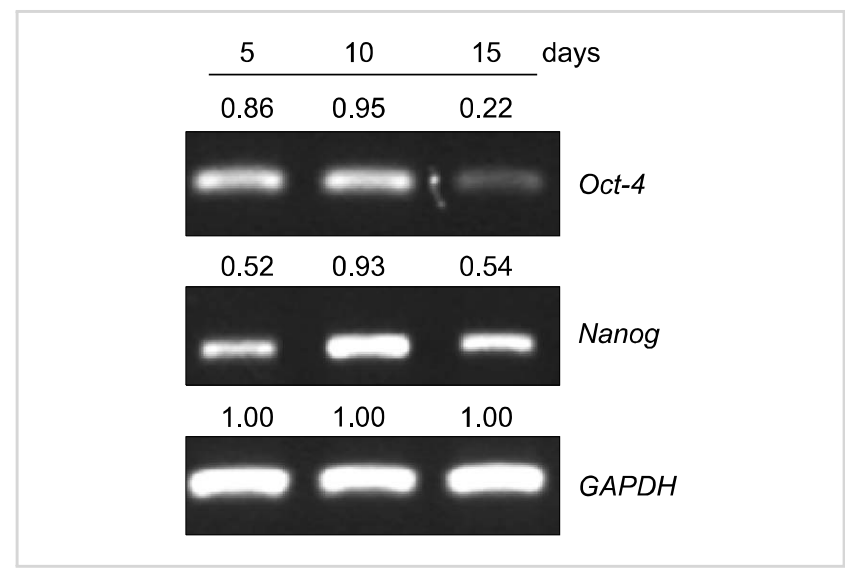

Fig. 5. Stemness gene expression by MSCs after seeding at 200 cells $/ \mathrm{cm}^{2}$. Total RNA of MSCs, obtained at 5-, 10-, and 15-day cultures after plating at a density of 200 cells $/ \mathrm{cm}^{2}$, was analyzed by RT-PCR with primers specific for Oct-4 and Nanog. Quantitative gene expression data of each candidate gene indicates mRNA expression relative to GAPDH mRNA.

preparations in terms of obtaining numerous cells, but these cells are more prone to produce lethal emboli when transplanted, possibly because they express cell adhesion proteins such as vascular cell adhesion molecule, and lack anti-cell adhesion proteins such as PODXL, and they therefore aggregate in the larger lung blood vessels [5]. Thus, the expression of these genes in MSCs may have a positive effect on both MSCs and their target cells in cell therapy settings.

Damaged tissues require the stemness and potent immunomodulatory properties of MSCs as a component of the therapeutic action of MSCs following a homing event for tissue reconstitution. The observed expression of Oct- 4 and Nanog in 10-day cultures after seeding at a density of 200 cells $/ \mathrm{cm}^{2}$ shows stem cell maintenance in the adult organism that is essential for tissue homeostasis and for initiation of native tissue regeneration and responses to injury [22]. Therefore, the identification of regulatory factors that maintain the "stemness" properties of MSCs is important for the practical purpose of producing sufficient quantities of MSCs for therapeutic applications. The anti-inflammation and immunomodulation exhibited by MSCs in their initiation of native tissue regeneration may also be important for tissue reconstitution in therapeutic settings. The inhibitory effect of MSCs on human mononuclear cell proliferation [20] and immunomodulatory gene expression of cultured MSCs when seeded at a low density indicates that MSCs retain their immunomodulatory properties in an inflammatory environment (i.e., in the presence of IFN- $\gamma$ ); this increases the possibility of protecting target stem cells and tissues, thereby supporting a possible use for MSCs in regenerative therapy under inflammatory conditions.

In conclusion, our results showed differences in the gene expression patterns of MSCs according to the seeding density and culture time. MSCs from 10-day cultures after seeding at a low density were efficiently expanded, expressed PODXL, $\alpha 6$-integrin, $\alpha 4$-integrin, and LIF, and retained their

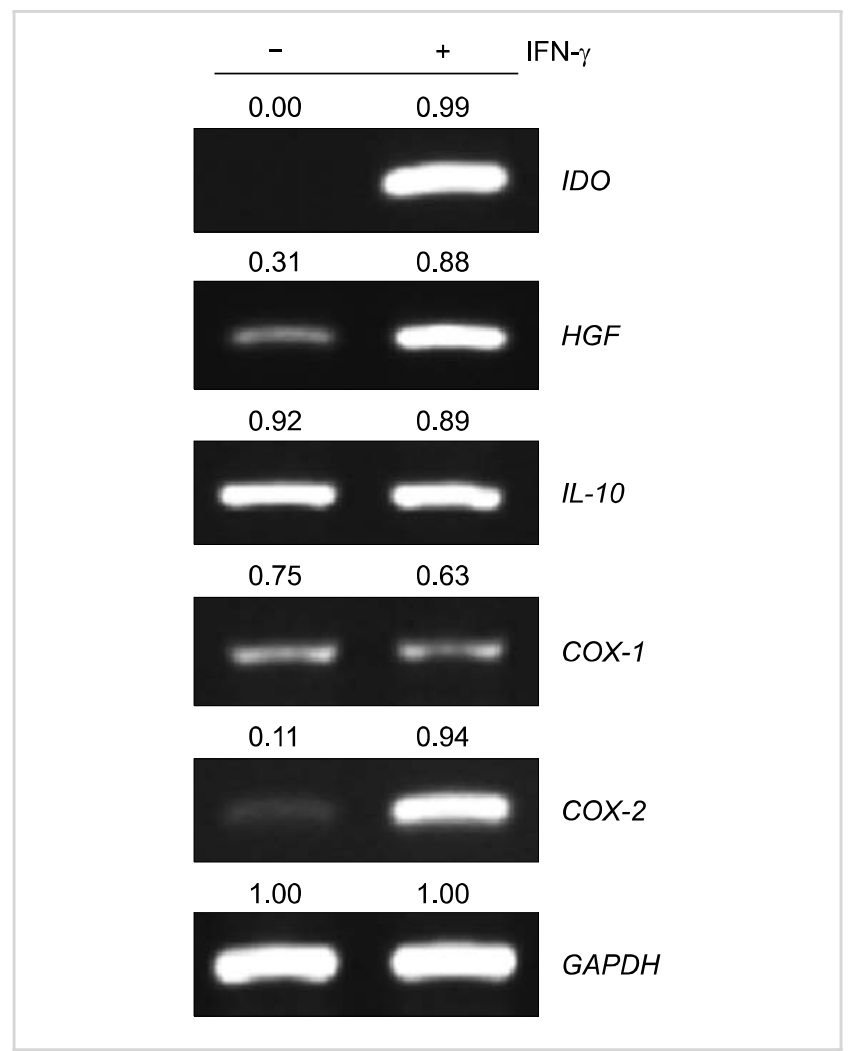

Fig. 6. Expression levels of immunomodulatory factors in MSCs cultured for 10 days after seeding at 200 cells $/ \mathrm{cm}^{2}$. MSCs were seeded at a density of 200 cells $/ \mathrm{cm}^{2}$ and cultured for 10 days, and then treated with or without IFN- $\gamma$ for $48 \mathrm{~h}$. Total RNA of these MSCs was analyzed by RT-PCR with primers specific for IDO, IL-10, HGF, COX-1, and COX-2. Quantitative gene expression data of each candidate gene indicates mRNA expression relative to GAPDH mRNA.

stemness and immunomodulatory gene expression. These data indicate that the seeding density and culture time are key factors in preparing MSCs for use in regenerative medicine. This study provides promising information on culture conditions appropriate for obtaining MSCs for cell therapy.

\section{Authors' Disclosures of Potential Conflicts of Interest}

No potential conflicts of interest relevant to this article were reported.

\section{REFERENCES}

1. Sasaki M, Abe R, Fujita Y, Ando S, Inokuma D, Shimizu H. Mesenchymal stem cells are recruited into wounded skin and contribute to wound repair by transdifferentiation into multiple skin cell type. J Immunol 2008;180:2581-7.

2. Toma C, Pittenger MF, Cahill KS, Byrne BJ, Kessler PD. Human mesenchymal stem cells differentiate to a cardiomyocyte phenotype in the adult murine heart. Circulation 2002;105:93-8.

3. Keyser KA, Beagles KE, Kiem HP. Comparison of mesenchymal 
stem cells from different tissues to suppress T-cell activation. Cell Transplant 2007;16:555-62.

4. Nauta AJ, Fibbe WE. Immunomodulatory properties of mesenchymal stromal cells. Blood 2007;110:3499-506.

5. Lee RH, Seo MJ, Pulin AA, Gregory CA, Ylostalo J, Prockop DJ. The CD34-like protein PODXL and alpha6-integrin (CD49f) identify early progenitor MSCs with increased clonogenicity and migration to infarcted heart in mice. Blood 2009;113:816-26.

6. Lee RH, Hsu SC, Munoz J, et al. A subset of human rapidly self-renewing marrow stromal cells preferentially engraft in mice. Blood 2006;107:2153-61.

7. Colter DC, Sekiya I, Prockop DJ. Identification of a subpopulation of rapidly self-renewing and multipotential adult stem cells in colonies of human marrow stromal cells. Proc Natl Acad Sci U S A 2001;98:7841-5.

8. Digirolamo CM, Stokes D, Colter D, Phinney DG, Class R, Prockop DJ. Propagation and senescence of human marrow stromal cells in culture: a simple colony-forming assay identifies samples with the greatest potential to propagate and differentiate. Br J Haematol 1999;107:275-81.

9. Smith JR, Pochampally R, Perry A, Hsu SC, Prockop DJ. Isolation of a highly clonogenic and multipotential subfraction of adult stem cells from bone marrow stroma. Stem Cells 2004;22:823-31.

10. Ho AD, Wagner W, Franke W. Heterogeneity of mesenchymal stromal cell preparations. Cytotherapy 2008;10:320-30.

11. Reyes M, Lund T, Lenvik T, Aguiar D, Koodie L, Verfaillie CM. Purification and ex vivo expansion of postnatal human marrow mesodermal progenitor cells. Blood 2001;98:2615-25.

12. Sotiropoulou PA, Perez SA, Salagianni M, Baxevanis CN, Papamichail M. Characterization of the optimal culture conditions for clinical scale production of human mesenchymal stem cells. Stem Cells 2006;24:462-71.

13. Qian H, Tryggvason K, Jacobsen SE, Ekblom M. Contribution of alpha6 integrins to hematopoietic stem and progenitor cell homing to bone marrow and collaboration with alpha4 integrins. Blood 2006;107:3503-10.

14. Patterson BK, Tjernlund A, Andersson J. Endogenous inhibitors of HIV: potent anti-HIV activity of leukemia inhibitory factor. Curr Mol Med 2002;2:713-22.

15. Pruijt JF, Lindley IJ, Heemskerk DP, Willemze R, Fibbe WE. Leukemia inhibitory factor induces in vivo expansion of bone marrow progenitor cells that accelerate hematopoietic reconstitution but do not enhance radioprotection in lethally irradiated mice. Stem Cells 1997;15:50-5.

16. Almeida-Porada G, Flake AW, Glimp HA, Zanjani ED. Cotransplantation of stroma results in enhancement of engraftment and early expression of donor hematopoietic stem cells in utero. Exp Hematol 1999;27:1569-75.

17. Furness SG, McNagny K. Beyond mere markers: functions for CD34 family of sialomucins in hematopoiesis. Immunol Res 2006;34:13-32.

18. Nasef A, Mazurier C, Bouchet $S$, et al. Leukemia inhibitory factor: Role in human mesenchymal stem cells mediated immunosuppression. Cell Immunol 2008;253:16-22.

19. O’Shea JJ, Ma A, Lipsky P. Cytokines and autoimmunity. Nat Rev Immunol 2002;2:37-45.

20. Yoo KH, Jang IK, Lee MW, et al. Comparison of immunomodulatory properties of mesenchymal stem cells derived from adult human tissues. Cell Immunol 2009;259:150-6.

21. Pricola KL, Kuhn NZ, Haleem-Smith H, Song Y, Tuan RS. Interleukin-6 maintains bone marrow-derived mesenchymal stem cell stemness by an ERK1/2-dependent mechanism. J Cell Biochem 2009;108:577-88.

22. Alison MR, Islam S. Attributes of adult stem cells. J Pathol 2009;217:144-60. 